\title{
ANALYSIS OF AGRICULTURAL LAND USE TRANSFORMATIONS IN GREECE: A MULTINOMIAL LOGISTIC REGRESSION MODEL AT THE REGIONAL LEVEL
}

\author{
D. MINETOS \& S. POLYZOS \\ Department of Planning and Regional Development, University of Thessaly, Volos, Greece.
}

\begin{abstract}
In the past few decades, numerous structural changes regarding the socio-economic basis of most EU countries have been profound and critical. These processes of economic restructuring have resulted in significant land use changes. As regards the agricultural sector, the overall changes in both Greece and the other European countries have been particularly intense in the last 20 years. Such changes include the massive reduction in the levels of employment in agriculture, shrinkage of the economic importance of the agricultural sector as a whole, changes in crop plants and cultivation practices, crucial implications arising from the new European Common Agricultural Policy and the growing competition due to low-cost agricultural products from developing countries. These changes have not had the same magnitude and impacts across all Greek regions. Instead, significant spatial variability relevant to the regional characteristics of each administrative prefecture can be observed. In this article, we carry out an empirical analysis focusing on agricultural land use patterns at a prefectural level for the whole country. The changes are tracked and analysed in terms of selective possible driving factors. The methodology adopted is multinomial logistic regression. Some policy implications are drawn with a regional perspective.

Keywords: agricultural land use, Common Agricultural Policy, land use changes, multinomial logistic regression, urbon sprawl.
\end{abstract}

\section{INTRODUCTION}

The most extensive type of land use in Greece is agriculture, with $49.5 \%$ of the Greek terrestrial area used for crop production and pastoral purposes [1]. In the last three decades, agricultural production practices have changed markedly and social, economic, political, scientific and technological progress have influenced considerably and reshaped the whole agricultural land use and production system [2,3]. Some key developments include new methods of production and adoption of innovations and new technologies, large-scale irrigation and increased inputs of fertilisers and pesticides, new crop types and cultivation practices, a Common Agricultural Policy (CAP) for all EU members as well as reductions in farm household numbers and farm employment, structural changes in the farm household income through the diversification of farm activities (e.g. agro-tourism) and off-farm employment and income. Currently, about $11.5 \%$ of farmers in Greece are classified by Eurostat as full time [4].

Multifunctionality of agriculture and rural areas, in general, has been an objective of policy incentives and regulations [5, 6]. It refers to both the diversification of on-farm activities and the generation of rural income in off-farm employment. To promote regional development of its member states and to speed up the process of convergence, the EU allocates substantial funds targeted at achieving greater economic and social cohesion as well as reducing disparities. In rural areas, these funds are especially targeted towards multifunctionality, influencing the established patterns of rural land uses [7]. In addition, recent reforms of CAP have resulted in a new challenge to cope with, that is, the incorporation of environmental objectives into agricultural operations [7, 8]. This challenge requires the sustainable use and management of environmental resources through the implementation of codes of good agricultural practices and environmentally sensitive and responsible food production operations.

Over the next 10-20 years, even more radical changes are expected to emerge. The Greek population, with the current rates of social, economic and scientific progress, will probably increase their needs 
for quality and safe food, produced in a way that society's environmental expectations are met. In addition, economic globalization processes and transportation advances have contributed to the production of a new geographic organization of agricultural locations, where competition increases as the new world trading regulations loosen protective policies through trade liberalization. The scene maybe even more complex in the near future, as the requirement for dealing with atmospheric pollution, global warming and climatic changes has increased the demand for biofuels [9].

Present agricultural patterns are the outcome of multiple socio-economic spatial processes that, some times, have caused irreversible damage to land and water resources. International concern about the adverse consequences of both agricultural intensification in some areas and agricultural abandonment in some other areas is rising [10]. A comprehensive impact assessment literature addresses the process of change in agricultural systems and the associated damages: desertification, biodiversity treats, forest land reduction, nitrogen pollution, land erosion, aquifer and surface water utilization and loss of heritage agricultural landscapes [11-14]. Certain EU policies as well as initiatives at the national level have tried to influence the direction of developments in the rural areas. Among them, the EU CAP has been the most important, widespread and controversial one attracting criticism because of its high cost on the EU budget and its questionable ability to deliver sustainable development in rural areas.

The rural sector continues to have an important role in the Greek economy, giving full-time and part-time employment to some 1.4 million people [15] of the active population and contributing to the gross national product (GNP) by 8\% for the year 2001 [15]. Almost 800,000 agricultural lots make up the Greek agricultural sector [15]. The majority of farms have small sizes and are placed on mountainous, insular or other marginal land. These areas have suffered from large-scale farmland abandonment resulting in significant biodiversity reduction and loss of historical landscapes. In the case of insular areas, recent mass tourism developments have taken up and still continue to transform large portions of agricultural land [16]. On the other hand, in productive plateau areas, there has been an intensive exploitation of land through the intensification of crop production. This has resulted in the reduction of crop diversity, homogenization of the rural landscape due to disappearing scattered strips of shrubs and bushes between the parcels of uncultivated land, increased inputs of fertilizers and pesticides and extensive use of ground and surface water for irrigation purposes.

The transformation of agriculture is partly due to subsidies and other provisions of the CAP and partly due to other factors like international trade reforms, market returns, new production practices and technological advances. Nevertheless, land use changes in the suburban and rural areas have been extensive [17]. These changes can be classified into two broad categories: (a) agricultural land use conversions, which refers to the complete change from agricultural use to another type of use, for example, urban or forest uses; and (b) agricultural land use modification, which refers to the expansion or intensification of agricultural use without loosing its initial character, for example, when adopting new technologies in the manipulation of agricultural land. Thus, land use modification implies structural or functional alterations in use without loosing its initial attributive characteristics.

A critical step in improving the way we approach land use changing patterns requires uncovering underlying causes and proving aetiological hypotheses, which are essential in order to formulate effective policy solutions [18]. The complexity of processes determining the current agricultural land use patterns cannot be fully understood in a simple manner. The use of parameters depends heavily on the level of spatial analysis, data availability and format and the specific questions to be answered. Thus, human institutions, population size and distribution, polulation's physical and behavioural characteristics, economic development indicators, technological status, and spatial and environmental characteristics such as soil types, slope, proximity to transportation networks and other factors have all been employed in the international literature in order to explain land use dynamics. 
This study primarily aims at revealing the major agricultural land use change trajectories in Greece and the possible underlying causes of change for a period of 10 years using the prefectural administrative level (NUTS III) as a spatial scale of analysis. The above aims are pursued through the estimation of the type and magnitude of relations between changes in agricultural land use and selective driving factors for the period 1991-2000. The methodology adopted is multinomial logistic regression analysis. This type of regression is useful for land use decisions that show some hierarchy or grouping as well as when the land use change data are not fully reliable [19]. The methodology does not necessarily assume linear relationships between the variables. The study finishes by drawing some conclusions regarding the results. These conclusions are made in the light of well-known theoretical schemata relevant to the field of land use change as well as by using logical reasoning and relevant past experience in the field.

The remainder of the article is organized as follows: Section 2 provides a framework for the empirical analysis by dealing with the agricultural land use driving factors and the theoretical schemata that describe the process of agricultural land use change. It gives a detailed description of the explanatory variable used in the empirical model and comments on the merits of using multinomial logistic regression as a tool for investigating changes in land uses. Section 3 describes the regional analysis of agricultural land use changes. The overall performance of the model is discussed and the results are presented and interpreted. Finally, Section 4 formulates the conclusions drawn from the precedent investigation.

\section{MATERIALS AND METHODS}

\subsection{Study area}

Greece covers a geographical area of $131,957.4 \mathrm{~km}^{2}$, has a population of about 10.9 million people and a population density of $78 / \mathrm{km}^{2}$ [1]. The mainland part of the country marks the end of the Balkan Peninsula, whereas the insular part (consisting of about 3,000 inhabited and uninhabited islands situated in the Aegean Sea as well as the Ionian Sea) borders with the Asian and African continents. The coastline stretches over a distance of approximately $15,021 \mathrm{~km}$. About $72.8 \%$ of the people live in urban areas and the remaining $27.2 \%$ in rural areas [1]. About $9.2 \%$ of the population live in mountainous areas, whereas in semi-mountainous and urban areas the figures are $21.8 \%$ and $69.0 \%$, respectively [1]. The country consists of 13 administrative regions. The regions are divided into 51 prefectures or counties, which include 900 large municipal districts and 133 small districts.

As regards land use distribution, agriculture and pastoral uses cover $49.5 \%$ of the country's surface, forests, shrub and bare land cover $47.2 \%$, inland water covers $1.3 \%$ and urban and other artificial surfaces cover $2.0 \%$ [1]. Geomorphologically speaking, most of the mainland territory consists of mountains. Just a few major agricultural plains exist, the largest of which is placed in central Greece within the administrative boundaries of the Thessaly region. Agricultural land use in the last decade (1991-2000) showed a reduction mainly affecting cultivated land [20]. This reduction brought about an increase of pastures and shrub land and forest land areas, while part of the cultivated land was adsorbed by urbanization. Figure 1 shows the geographic distribution of agricultural land use changes (in ha) for the prefectures classified into three categories: (a) low agricultural land use change, where the change is zero or slightly negative $(<8 \%)$; (b) medium agricultural land use change, where the change is negative and is $\geq 8 \%$ and $\leq 15 \%$; and (c) high agricultural land use change, where the change is negative and is $>15 \%$. It is obvious that most of the west coast of the country and the whole Peloponnesus are designated as areas of high or medium agricultural land use changes. The island of Crete, most of the Aegean Sea islands, Attiki, Evia and Magnesia (see Table 1 to spot place names) 


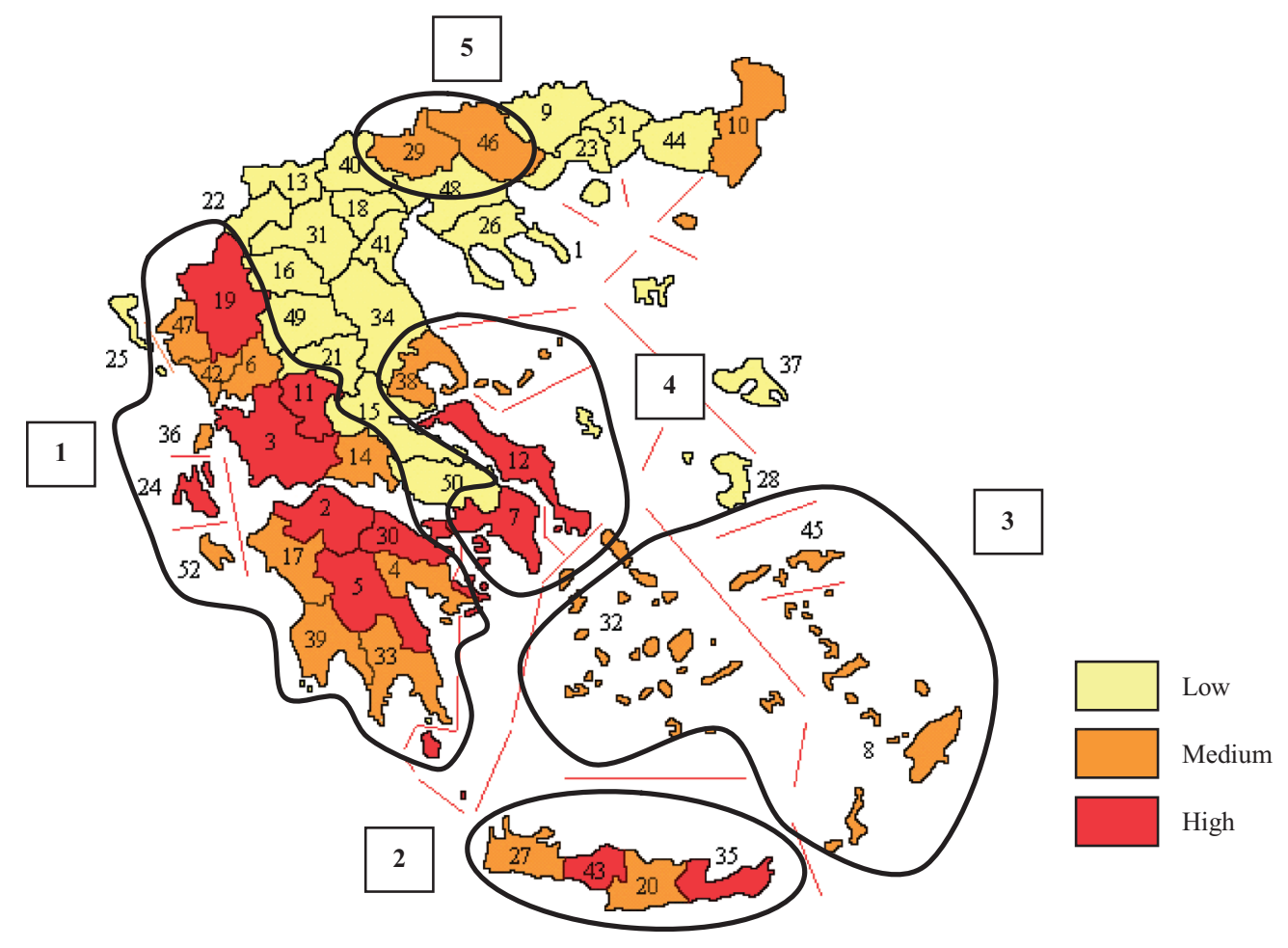

Figure 1: Spatial distribution of agricultural land use changes in Greece for the period 1991-2000.

Table 1: The study units - NUTS III administrative divisions (prefectures).

\begin{tabular}{llllllll}
\hline No. & Name & No. & Name & No. & Name & No. & Name \\
\hline 1 & Agion Oros* & 14 & Fokida & 27 & Chania & 40 & Pella \\
2 & Achaia & 15 & Fthiotida & 28 & Chios & 41 & Pieria \\
3 & Aitoloakarnania & 16 & Grevena & 29 & Kilkis & 42 & Preveza \\
4 & Argolida & 17 & Ilia & 30 & Korinthia & 43 & Rethimno \\
5 & Arkadia & 18 & Imathia & 31 & Kozani & 44 & Rodopi \\
6 & Arta & 19 & Ioannina & 32 & Kyklades & 45 & Samos \\
7 & Attiki & 20 & Irakleio & 33 & Lakonia & 46 & Serres \\
8 & Dodekanisos & 21 & Karditsa & 34 & Larisa & 47 & Thesprotia \\
9 & Drama & 22 & Kastoria & 35 & Lasithi & 48 & Thessaloniki \\
10 & Evros & 23 & Kavala & 36 & Lefkada & 49 & Trikala \\
11 & Evrytania & 24 & Kefallinia & 37 & Lesvos & 50 & Viotia \\
12 & Evia & 25 & Kerkyra & 38 & Magnisia & 51 & Xanthi \\
13 & Florina & 26 & Chalkidiki & 39 & Messinia & 52 & Zakinthos \\
\hline
\end{tabular}

*This area was not included in the analysis. 
in the central part of the country and Kilkis and Serres to the north of Thessaliniki have also suffered considerable reductions in their agricultural land. Table 2 summarizes the cases with the lowest and highest reductions in agricultural land uses.

\subsection{Land use antagonism: the major agricultural land use change pathways}

Changes in agricultural land use and land cover reflect economic causes, policy measures as well as spatial planning objectives and show a wide range of impacts, including biophysical and socio-economic changes and feedbacks between land use and its drivers. In order to understand future developments in agricultural land use and their effects, it is essential to thoroughly analyse and interpret past and current land use patterns. Land use competition is possible to have both positive (i.e. increase in agricultural land) and negative effects (namely decrease in agricultural land). In turn, this might lead to agricultural land expansion in some places and agricultural land shrinkage in some others.

There is a conceptual framework in Fig. 2, providing an overview of land system changes as well as their relevance with human decision system. Complex human decisions deriving from individuals, households and various social groups create multisectoral phenomena such as urban sprawl, migration from rural areas and distinctive locational patterns of industry and tourism. All these have an effect on the distribution of land uses giving rise to processes of change. Below, we describe the major agricultural land use change trajectories in Greece.

- Agricultural land uses to urban land uses through tourism urbanization, urban sprawl and town planning extensions: In the last two decades, most of the tourism development and new tourism infrastructure have taken place on agricultural land. This is because developing such facilities on forest land is considered illegal, although it has happened in certain cases. Institutionally speaking, forests and forest land areas have a strong degree of protection under the Hellenic Constitutional principal (articles 24 and 117, 1975/86/00) 'forest use can change only for the public interest and only in cases in which the public interest cannot be accommodated by alternative means that do not include forest land use change'. Tourism development especially in the coastal areas and on the islands is a major driver of agricultural land urbanization. Furthermore, extensions of city and town plans are usually performed at the expense of suburban agricultural land. These processes consume agricultural land as long as urban uses are more profitable than agricultural land uses.

- Agricultural land uses to pastoral and forest land uses through the abandonment of cultivated land and the introduction of afforestation policies of rural areas: In the past few decades, there has been large-scale abandonment of farmland in many Greek as well as other European regions [21, 22].

Table 2: Areas with minimum and maximum agricultural land use changes.

\begin{tabular}{|c|c|c|c|}
\hline \multicolumn{2}{|c|}{$\begin{array}{l}\text { Areas with the lowest change in agricultural } \\
\text { land for the period 1990-2000 }\end{array}$} & \multicolumn{2}{|c|}{$\begin{array}{l}\text { Areas with the highest change in agricultura } \\
\text { land for the period 1990-2000 }\end{array}$} \\
\hline Prefecture name & Value* & Prefecture name & Value* \\
\hline Larisa & 0.99 & Evritania & 0.55 \\
\hline Pella & 0.97 & Chios & 0.56 \\
\hline Florina & 0.97 & Lasithi & 0.63 \\
\hline Kozani & 0.96 & Ioannina & 0.64 \\
\hline Rodopi & 0.96 & Attiki & 0.65 \\
\hline
\end{tabular}

*The ratio of total agricultural land (ha) for the year 1990 to the total agricultural land for the year 2000. 


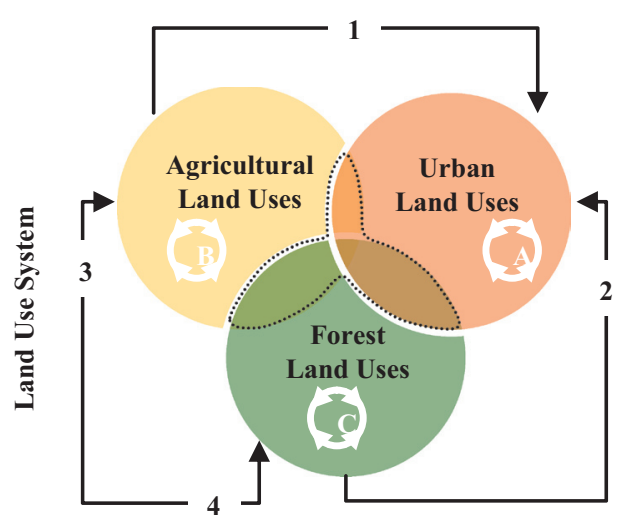

Area of Land Use Change Processes

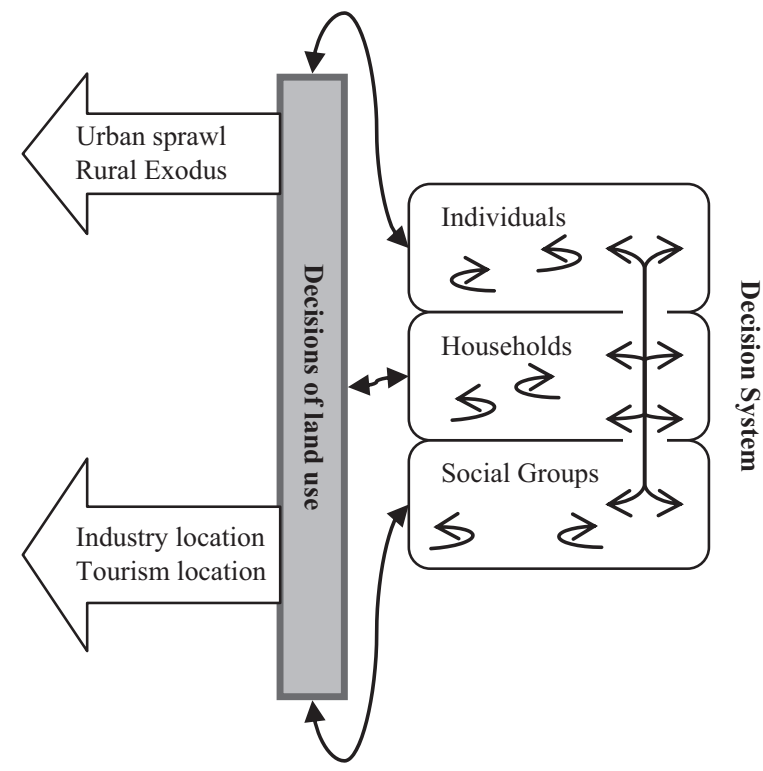

Figure 2: Conceptual framework of land use changes and human decisions.

Marginal land in mountainous areas and on the islands, cultivated in the past by adopting traditional cultivation practices such as the 'terrace-system' in Greece, are being driven away from agriculture. In fact, this land, in addition to native shrublands and other early successional habitats, is put to pastoral uses. Abandoned agricultural lands through succession processes turn into grasslands and shrublands in the extremely dry areas of the islands and coastal locations. In these places of high aeolian energy, salt spray and arid conditions, shrub-dominated communities may be the climax.

- Forest and pastoral land uses to agricultural land uses: Expansion of cultivation is likely to occur into previously uncultivated areas of either forest or pastoral uses. Changes in the technological level of agriculture that make agricultural land more profitable as a result of crop output increases or labour and capital savings promote forest clearing [23] and pastoral land use conversion. In present-day landscapes, near productive flat areas, there has been a significant expansion of agricultural land uses so that the most frequent disturbance in these areas is the encroachment of agriculture into valley forests. Spatially and temporally isolated patches of shrubland and maquis vegetation are disappearing.

\subsection{Modelling agricultural land use and its determinants}

Following the above discussion, we developed an empirical model to simulate agricultural land use developments in Greece on a prefectural level of analysis (NUTS III) from 1990 to 2000. The major factors controlling agricultural land use change processes are relevant to the aforementioned land use change trajectories and fall into the categories of economy and technology-related factors, population-related factors and environment-related factors. Underneath, we give an overview of the factors chosen to construct the model. 


\subsubsection{The dependent variable}

Variable $Y$ - agricultural land use change: The dependent variable of agricultural land use change represents the ratio of the land allocated to agriculture in 1990 to the land in agriculture in 2000. This ratio defines the change in agricultural land at a prefectural level. Data for this variable come from two surveys of National Statistical Service of Greece (NSSG), conducted in 1990 and 2000 [15, 24].

The normal probability Q-Q plot (Fig. 3) shows that the variable is not normally distributed. We can see that there are a lot of values above and below the predicted normal line. The detrended normal Q-Q (Fig. 3) plot depicts the differences between the observed and the predicted values. When the distribution of the values of the dependent variable is normal, the values of the difference between observed and predicted fall randomly about the zero line. This is not the case here. There are groups of values far above and below the zero line. Therefore, the distribution of the values of the depended variable is not symmetric.

Looking at the histogram of the dependent variable in Fig. 4, we can see that the distribution is not symmetric. There is a peak on the right-hand side and also the distribution is skewed to the left having a tail towards larger 'agricultural land use reduction' values. That is why we constructed three classes of agricultural land use change prefectures.

The first class represents the prefectures under the peak that have managed to sustain most of their agricultural land. The cut point here is $8 \%$. The second class represents the prefectures with medium agricultural land losses. The cut point here is $15 \%$. Finally, the last class represents the remaining prefectures of high agricultural land losses under the left tail of the distribution.

Examining the stem-and-leaf plot and the box-plot in Fig. 4, we can acquire more information about the tail of the distribution. In the stem-and-leaf plot, we can see that there are three extreme values with losses in their land over $34 \%$. As regards the box-plot, the whiskers that extend from the right and left of the box represent the smaller and largest values that are outliers. The prefectures with the highest losses in their agricultural land are Evritania, Chios and Lasithi.

\subsubsection{The independent variables}

The factors chosen for the empirical analysis are selective economic, social and environmental indicators. In particular, these were:
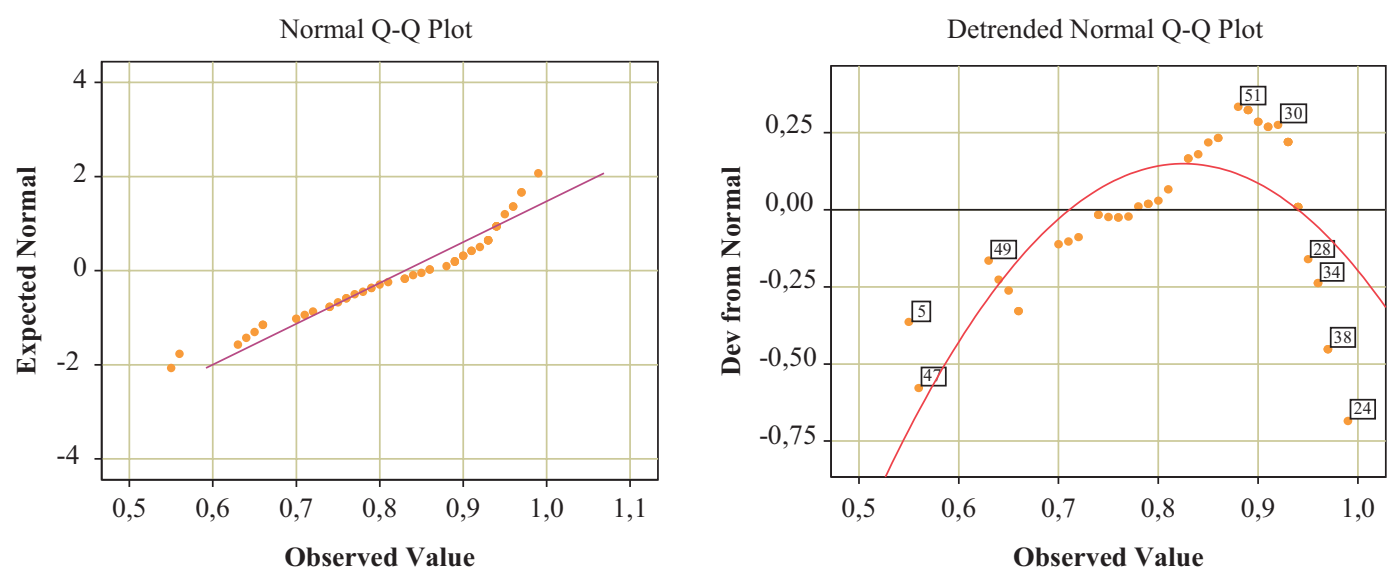

Figure 3: Normal Q-Q and detrended normal Q-Q plots of agricultural land use changes. 


\begin{tabular}{|c|c|}
\hline Frequer & Stem and Leaf \\
\hline 10.00 & 0. 2445556679 \\
\hline 21.00 & 1. 001122234445567777889 \\
\hline 6.00 & 2. \\
\hline & 012456 \\
\hline 5.00 & 3. 13457 \\
\hline 2.00 & 4. 33 \\
\hline 4.00 & 5. 0358 \\
\hline 3.00 & xtremes $\quad(\geq 751868)$ \\
\hline
\end{tabular}

Stem width: 100000,0

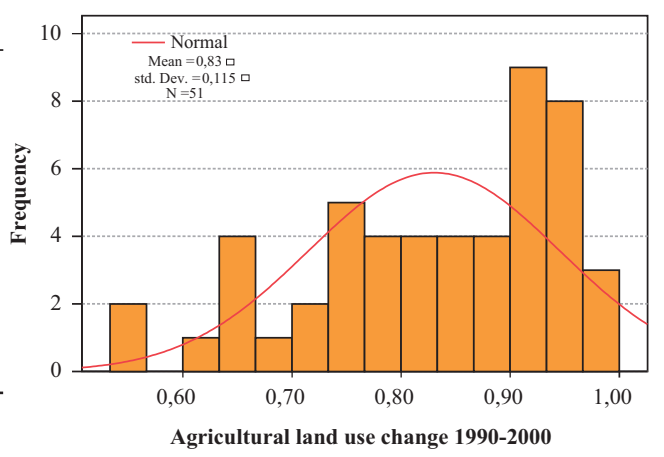

Agricultural land use change 1990-2000

Each leaf: 1 case(s)

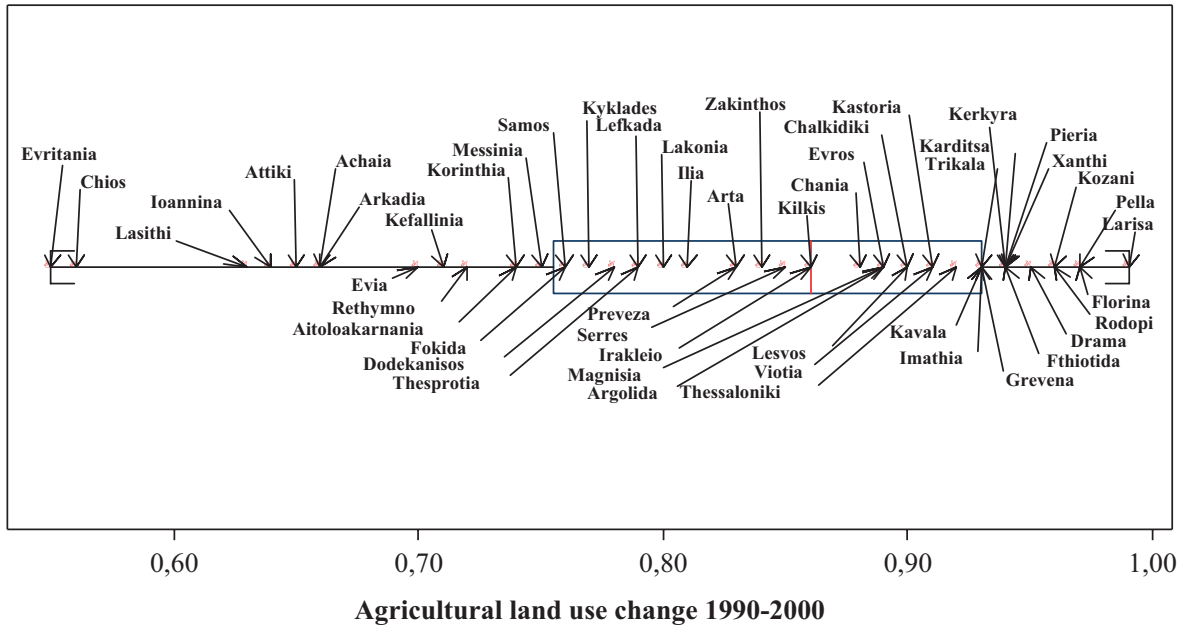

Figure 4: Stem-and-leaf plot, histogram and box-plot of the values of agricultural land use change (the values represent the \% area that sustained its use between 1990 and 2000).

- Variable $X_{1}$ - urban sprawl: The data for this variable come from the NSSG $[25,26]$ and refer to the percentage of buildings constructed outside the existing urban plans in each prefecture for the year 2000. The indicator is the ratio of the number of buildings constructed outside the existing urban plans in a prefecture multiplied with 100 to the total number of buildings in that prefecture. This is a proxy variable for total urban sprawl in each prefecture. Urban sprawl adverts to the expansion of urban uses to less developed areas usually in the periphery of the cities [27]. It is a typical process of consuming substantial portions of agricultural land in relation to traditional urban developments because of the low-density areas created. The basic mechanism of land use allocation behind this process lies in land-rent theories of von Thünen and of Ricardo. These theoretical schemata suggest that any parcel of land is ultimately used in the way that generates the highest rent [28, 29]. Therefore, it is expected that increases in urban land will have a negative impact on agricultural land. This maybe particularly true for Greece where changes in forest land use in favour of urban uses are restricted. In addition, the current land use planning framework in Greece does not adequately protect agricultural land from urban expansion. 
- Variable $X_{2}$-forest land use change: This variable represents the change in forest land for the period 1990-2000 in a prefectural level. The change is expressed by the ratio of the total area of forest land for the year 1990 to the total area of forest land for the year 2000 in each prefecture. Data for this variable come from two surveys of NSSG [15, 24]. However, there are arguments concerning the compatibility of the two surveys as the NSSG uses different classification categories as regards forest land data between the two surveys. In the past, forest propagation due to abandonment of farmland has happened to a substantial number of Greek prefectures and in particular in the mountainous and semi-mountainous prefectures. After abandonment of farmland, there is a succession process with the first stage dominated by herbaceous plants. Although rear, the expansion of cultivation on formerly forest land is also true in some cases when the soil conditions are favourable. However, when the lost forest land is not suitable for agricultural purposes, we expect that there is not enough interest for converting forest land to agricultural land.

- Variable $X_{3}$ - change in rural population in the period 1991-2001: The rural population variable represents the change in non-urban population in each prefecture. It is the ratio of the rural population in the year 1991 to the rural population in the year 2001. Data come from the NSSG [30, 31]. According to Zelinsky's theory of rural-urban migration [32], there are certain stages in migration that depend on the state of the society at that stage. One of his suggested stages involves the emergence of considerable rural-urban migration mostly in societies experiencing developing processes. In this stage, the flow of migrants increases considerably the demand for urban space at the expense of other uses. This was the case in Greece for the period shortly after the World War II which was characterized by massive rural-urban migration movement [33]. As the country reaches the developed stage, rural-urban migration may continue but at a reduced rate. In advanced societies, the mobility of people is continuous but in the form of inter- or intra-urban migration. Technological breakthroughs and transportation improvements are expected to reduce this kind of migration. In fact, we might have the opposite phenomenon of rural rebound where people seek dwellings in peri-urban or even rural locations despite the fact that they work in cities.

- Variable $X_{4}$-total population potential: The total population potential incorporates the indirect and the direct population potential and shows the total accessibility of each prefecture. The total (TPP) and the indirect population potential (IPP) are indicators of population agglomerations in each prefecture and of the total accessibility of each prefecture in relation to the other prefectures. These two figures are estimated by using the following formulas:

$$
\mathrm{TPP}_{i}=\frac{P_{i}}{d_{i i}}+\mathrm{IPP}_{i} \Rightarrow \mathrm{TPP}_{i}=\frac{P_{i}}{d_{i i}+\sum_{j}^{n-1}\left(P_{j} / d_{i j}\right)}
$$

where $P_{i}$ is the population of prefecture $i, P_{j}$ is the population of prefecture $j, d_{i i}$ represents the distances within the prefecture $i$ and $d_{i j}$ represents the distances between the prefectures $i$ and $j$. The data for this variable come from a previous research by Polyzos and Arambatzis [34]. We use this indicator because very often the changes in the use of land in a location are generated by people who live and work away from that location [35]. For instance, inhabitants of large urban concentrations sometime build houses or invest in adjacent prefectures (e.g. dwellers from Thessaloniki build houses in Pieria or Chalkidiki, dwellers from Athens in Evia or Korinthia). We expect that if a prefecture has a large population potential, it will influence the agricultural land uses substantially.

- Variable $X_{5}$ - changes in irrigated areas: This variable represents the change in irrigated areas for the period 1990-2000 in a prefectural level. The change is expressed by the ratio of the amount of 
irrigated land for the year 1990 to the amount of irrigated land for the year 2000 in each prefecture. Data for this variable come from two surveys of NSSG [15, 24]. The surface area occupied by irrigated crops is a main indicator of water resources availability. Irrigation usually affects positively the crop yield and the profitability of the agricultural sector. Therefore, we expect that in the prefecture with increased irrigated areas, the decrease in agricultural land would be less likely.

- Variable $X_{6}$ - changes in the hotel beds: The relationship between tourism and agricultural land use change is examined by means of the proxy variable 'changes in hotel bed'. This variable represents the change in hotel beds for the period 1990-2000 in a prefectural level. The change is expressed by the ratio of the number of hotel beds for the year 1990 to the number of hotel beds for the year 2000 in each prefecture. Data for this variable come from two surveys of NSSG, conducted in 1990 and 2000. Modern tourism infrastructure results in profound changes to the landscape, especially on the coastal and insular locations. We expect that large changes in tourism hotel infrastructure would have a detrimental effect on agricultural land by increasing the demand for urban land. However, from a sustainability perspective, tourism and leisure facilities should be seen critically because rural tourism can be a vehicle for sustainable development.

- Variable $X_{7}$-changes in the gross domestic product $(G D P)$ in agriculture: This variable represents the change in the GDP in agriculture to the GNP in agriculture for the period 1990-2000 in a prefectural level. The changes are estimated by using the following formula:

$$
\frac{\mathrm{GDP}_{\mathrm{AGR} \_1990 \_i}}{\mathrm{GNP}_{\mathrm{AGR} \_1990}} / \frac{\mathrm{GDP}_{\mathrm{AGR} \_2000 \_i}}{\mathrm{GNP}_{\mathrm{AGR} \_2000}}
$$

where GDP $\mathrm{ARG}_{\mathrm{AR} 199{ }_{i} i}$ is the mean GDP in agriculture for the years 1989, 1990 and 1991 in the prefecture $i$; $\mathrm{GDP}_{\mathrm{ARG}_{2} 2000 i}$ is the mean GDP in agriculture for the years 1999, 2000 and 2001 in the prefecture $i$; $\mathrm{GNP}_{\mathrm{ARG} \_1990}$ is the mean GNP in agriculture for the years 1989, 1990 and 1991; and $\mathrm{GNP}_{\mathrm{ARG} \_2000}$ is the mean GNP in agriculture for the years 1999, 2000 and 2001. Data for this variable come from the NSSG. We expect that the growth of GDP in the agricultural sector will decrease the likelihood of agricultural lands being abandoned.

- Variable $X_{8}$ - level of prosperity in each prefecture: The prosperity indicator has been estimated by using the official data for the Greek prefectures by Eurostat concerning the contribution of each prefecture to the GNP of Greece and to GNP per capita in $€$ as well as in Purchasing Power Standards. As the per capita GNP cannot give a safe estimation of the prosperity in the NUTS II and III levels, they have been incorporated into the variable additional financial and development indicators concerning the levels of consumption and civil infrastructure in the prefectures. The data concerning this variable come from a previous study by Petrakos and Polyzos [36]. By using this variable, we investigate whether the level of human prosperity in each prefecture is connected to agricultural land use changes or the changes in agriculture do not depend on the level of economic development of each prefecture.

- Variable $X_{9}$ - investment in the agricultural sector: This variable depicts the investments in machinery and infrastructure in the cultivated land plots in each prefecture. The variable refers to the mean investments for the period 1998-2001 in each prefecture. Data for this variable come from NSSG's annual table on agricultural investment. Investments make agriculture more capital intensive and thus more profitable and help finance putting additional land into production. So, in the prefectures where investments in agriculture are substantial, it is expected that there will be an increase or at least a stable state in the cultivated land surface.

- Variable $X_{10}$ - rate of livestock production: This variable illustrates the level of the GDP in the livestock sector for each prefecture. The variable refers to the mean GDP in the livestock sector for the 
period 1998-2001 in each prefecture. Data for this variable come from NSSG annual table on livestock production. Extensive grazing systems are common in the arid/semi-arid areas of the country. Increased livestock production may put pressure on existing cultivated land for new pastures. On the other hand, indoor production systems increase the demand for cropping feed resources. We expect that this variable will reveal any major interactions between animals and cultivated areas.

- Variable $X_{11}$ - geographical zone: By using this variable, we investigate whether the geographical position of a prefecture has an effect on the agricultural land use change. We expect that the geographical position of the cultivated areas, due to the variations in climatological conditions, may have an effect on the agricultural land use change by influencing the crop type and the profitability of the agricultural activity. Mild climatic environments combined with irrigation facilities result in increased agricultural yield and a great variety of crops. Therefore, the 51 prefectures have been allocated in three zones. The first zone includes the prefectures in the northern part of the country. Although these areas have some flat areas, they are mainly dominated by mountainous terrains and the climatic conditions are cold. The second zone includes the prefectures situated in the central part of the country. Here, a major portion of the land is flat and fertile and the climatic conditions are mild. Finally, the third zone encompasses the prefectures of the southern part of the country as well as most of the islands. Data for this variable come from NSSG [1].

\subsection{Methodology}

To study the impacts of the aforementioned variables on the agricultural land use change, appropriate modelling approaches are necessary. The methodology we choose is multinomial (or polychotomous) logistic regression which is a variation of ordinary regression. It is used when the dependent variable is categorical and the explanatory variables are continuous, or if categorical estimates of the probability of a certain land use occurring and can be used to present data of land use, to calculate the coefficients of the mathematical formula and then apply the coefficients to grid cells representing vacant land, yielding land use probability surfaces [19]. After transforming the dependent into logit variables (one logit less than the classes of the dependent variable), the multinomial logistic regression applies maximum likelihood estimation.

This type of regression does not assume that the relationship between the explanatory variables and the dependent variable is a linear one [37, 38]. Furthermore, it does not assume homoscedasticity and that the dependent and independent variables or the error terms are distributed normally. The only assumptions of the model are that the observations are independent and that the independent variables are linearly related to the logits of the dependent variable. The benefit of using a multinomial logistic model is that it models the odds of each subcategory relative to a baseline category as a function of covariates. It can test the equality of coefficients even if confounders are different unlike in the case of pair-wise logistics, where testing equality of coefficients requires assumptions about confounder effects. Several studies in the relevant land use change literature adopted this methodology. Morita et al. [39] used a multinomial logit model to assess changes in land use by type in Japan. The dependent variable was a four-dimensional vector of land use ratios, representing farmland, forest, built-up areas and other areas. The study area was divided into cell units and the probability of choice of a particular land use type in each of the cells was estimated. In doing so, they used a group of explanatory variables concerning economic, social and environmental factors. In another study, Chowdhury [40] applied multinomial logit regression in order to evaluate the socio-economic and biophysical forces driving deforestation processes in the southern Yucatán peninsular region, Mexico. In Sonoma County, California, Newburn et al. [41], in a study concerning purchasing land and 
easements for conservation purposes, employed a multinomial logit model to explain land use transitions as a function of parcel site and neighbourhood characteristics. Estimated coefficients from the multinomial logistic regression are employed to predict the relative probability of land use change since the site characteristics are known.

In our study, data for agricultural land use changes from 1990 to 2000 were derived from two Agriculture and Livestock Censuses carried out by the NSSG [24, 42]. The lowest spatial resolution of the data was at the prefectural level (NUTS III) though there were data at a lower spatial level available only for the period prior to 2000. Therefore, it was not possible to investigate agricultural land use changes at a lower spatial level of analysis by using this data set. In addition, the data collection procedure between the census of the year 2000 and the previous censuses had changed. A new land use classification scheme (i.e. new collection instrument) was adopted by the NSSG in the 2000 census and the data collection technique was also different (instead of using questionnaires, the land use data were derived by remotely sensed images). Hence, the data had to be transformed in order to be compatible.

Instead of using the agricultural land use change data as a continuous variable, we transform it into a categorical variable in order to account for errors in recording agricultural land use changes $[43,44]$. The prefectural agricultural land use change is used as a dependent variable, namely the percentage decline or increase. Therefore, in the dependent variable, we have the following categories:

- Low agricultural land use change, where the change of the area is zero or slightly negative $(<8 \%)$.

- Medium agricultural land use change, where the change is negative and is $\geq 8 \%$ and $\leq 15 \%$.

- High agricultural land use change, where the change is negative and is $>15 \%$.

Therefore, we have three categories with the low category being the reference category. The empirical model with $j$ categories of dependent variable can be expressed as:

$$
\ln \left[\frac{p(i \text {-category })}{p(j \text {-category })}\right]=b_{i 0}+b_{i 1} X_{1}+b_{i 2} X_{2}+\cdots+b_{i n} X_{n}+e_{i}
$$

where $p(i$-category) is the likelihood, the dependent variable being in the $i$ category; $p$ ( $j$-category) is the likelihood, the dependent variable being in the $j$ category (the baseline category); $X_{n}$ are the explanatory variables $1, \ldots, n$, employed by the empirical model; $b_{i 0}$ is the intercept for logit $i$; and $b_{i n}$ is the regression coefficient of the variable $n$ for logit $i$.

In the case of agricultural land use change with three categories, there are two non-redundant logits that can be expressed as following:

$$
\begin{aligned}
\text { LOGIT } 1 & =\ln \left[\frac{p(\text { AGR-Medium })}{p(\text { AGR-Low })}\right] \\
& =b_{\mathrm{MED} 0}+b_{\mathrm{MED} 1} X_{1}+b_{\mathrm{MED} 2} X_{2}+\cdots+b_{\mathrm{MED} 10} X_{10}+e_{i} \\
\text { LOGIT } 2 & =\ln \left[\frac{p(\text { AGR-High })}{p(\text { AGR-Low })}\right] \\
& =b_{\mathrm{HIG} 0}+b_{\mathrm{HIG} 1} X_{1}+b_{\mathrm{HIG} 2} X_{2}+\cdots+b_{\mathrm{HIG} 10} X_{10}+e_{i}
\end{aligned}
$$

Therefore, we calculate the parameter estimates for the above logits. The first logit expresses the $\log$ of the ratio of the probability of a prefecture being in the 'medium agricultural land use change' 
category compared to being in the baseline category (i.e. low agricultural land use change). Similarly, the second logit expresses the log of the ratio of the probability of being in the "high agricultural land use change' category compared to being in the baseline category (i.e. low agricultural land use change).

\section{RESULTS AND DISCUSSION}

\subsection{Model fitting information}

According to the observed values, the model has classified 20 prefectures as being in the 'low agricultural land use change' category, 19 prefectures in the medium agricultural land use change category and 12 prefectures of being in the high agricultural land use change category (Table 3 ).

In addition, from the likelihood ratio test (Table 4) for the overall model, we can see that the significance level is small and, therefore, we can reject the null hypothesis that all coefficients are 0 [38]. Hence, we can conclude that the model is significantly better than the intercept-only model (Table 4). Larger pseudo $R^{2}$ statistics indicate that more of the variation is explained by the model, to a maximum of 1 . In our model, all the pseudo $R^{2}$ statistics are relatively high.

The likelihood ratio tests (Table 5) check the contribution of each effect to the model. For each effect, the $-2 \log$ likelihood is computed for the reduced model; that is, a model without the effect. If the significance of the test is small $(<0.10)$, then the effect contributes to the model. This test can be used instead of Wald test presented in Table 7. This is because the Wald test sometimes fails to

Table 3: Case processing summary, model fitting information and pseudo $R^{2}$.

\begin{tabular}{lcc}
\hline & $N$ & Marginal percentage \\
\hline Agricultural categories & & \\
$0=$ low & 20 & 39.2 \\
$1=$ medium & 19 & 37.3 \\
$2=$ high & 12 & 23.5 \\
Valid & 51 & 100.0 \\
\hline
\end{tabular}

Table 4: Model fitting information and pseudo $R^{2}$.

\begin{tabular}{lclccc}
\hline Model & Model fitting criteria & & \multicolumn{3}{c}{ Likelihood ratio tests } \\
\cline { 2 - 2 } \cline { 5 - 6 } & -2 log likelihood & & $\chi^{2}$ & df & Significance \\
\hline Intercept only & 109.690 & & & & \\
Final & 51.251 & & 58.439 & 22 & 0.000 \\
Pseudo $R^{2}$ & & & & 0.682 \\
Cox and Snell & & & & 0.772 \\
Nagelkerke & & & & 0.533 \\
McFadden & & & & \\
\hline
\end{tabular}


Table 5: Likelihood ratio tests.

\begin{tabular}{lcrcc}
\hline Effect & Model fitting criteria & \multicolumn{3}{c}{ Likelihood ratio tests } \\
\cline { 3 - 5 } & -2 log-likelihood of reduced model & $\chi^{2 *}$ & df & Significance \\
\hline Intercept & 51.897 & 0.646 & 2 & 0.724 \\
$X_{1}$ & 54.940 & 3.689 & 2 & 0.040 \\
$X_{2}$ & 59.053 & 7.802 & 2 & 0.020 \\
$X_{3}$ & 55.151 & 3.900 & 2 & 0.142 \\
$X_{4}$ & 65.174 & 13.922 & 2 & 0.001 \\
$X_{5}$ & 57.672 & 6.420 & 2 & 0.040 \\
$X_{6}$ & 51.651 & 0.400 & 2 & 0.819 \\
$X_{7}$ & 52.969 & 1.718 & 2 & 0.424 \\
$X_{8}$ & 54.958 & 3.707 & 2 & 0.157 \\
$X_{9}$ & 57.542 & 6.291 & 2 & 0.043 \\
$X_{10}$ & 57.227 & 5.975 & 2 & 0.050 \\
$X_{11}$ & 72.765 & 21.514 & 2 & 0.000 \\
\hline
\end{tabular}

*The $\chi^{2}$ statistic is the difference in $-2 \log$-likelihoods between the final model and a reduced model. The reduced model is formed by omitting an effect from the final model. The null hypothesis is that all parameters of that effect are 0 .

correctly reject the null hypothesis when coefficients are large. The significance values of the test for the variables $X_{1}, X_{2}, X_{4}, X_{5}, X_{9}, X_{10}$ and $X_{11}$ are $<0.10$ and in some cases $<0.05$, so we can conclude that they are important factors for the formation of dependent variable. All other variables have large value of significance $(>0.10)$, so we can consider them not important factors.

The classification table shows the practical results of using the multinomial logistic regression model [38]. Cells on the diagonal are correct predictions, whereas cells off the diagonal are incorrect predictions (Table 6). Of the cases used to create the model, 16 of the 20 prefectures of the "baseline category' are classified correctly. Similarly, 13 of the 19 prefectures in the 'medium agricultural land use change' category are classified correctly. Finally, 9 of the 12 prefectures of the 'high agricultural land use change' category are classified correctly. Overall, $74.5 \%$ of the cases are classified correctly. That means that the model excels at identifying prefectures which experience 'low agricultural land use change' $(80.0 \%)$ and 'high agricultural land use change' $(75.0 \%)$. Prefectures in the medium category are identified in a percentage of $68.4 \%$ which is slightly lower. The classification results show that the model could be improved at classifying medium agricultural land use change prefectures. Thus, more research maybe required to determine some other predictor variables that classify better these prefectures.

\subsection{Parameter estimates}

The parameter estimates table (Table 7) summarizes the effect of each predictor variable. The ratio of the coefficient to its standard error, squared, equals the Wald statistic. If the significance level of the Wald statistic is small $(<0.05)$, then the parameter is different from 0. Parameters with significant negative coefficients decrease the likelihood of that response category with respect to the reference category. Parameters with positive coefficients increase the likelihood of that response category. The $\operatorname{Exp}(\mathrm{B})$ column reports the change in the odds of a prefecture being in the medium or high category 
Table 6: Classification.

\begin{tabular}{lcccc}
\hline Observed & \multicolumn{4}{c}{ Predicted } \\
\cline { 2 - 5 } & 0 & 1 & 2 & Percent correct \\
\hline 0 & $\mathbf{1 6}$ & 3 & 1 & 80.0 \\
1 & 4 & $\mathbf{1 3}$ & 2 & 68.4 \\
2 & 1 & 2 & $\mathbf{9}$ & 75.0 \\
Overall percentage & 41.2 & 35.3 & 23.5 & 74.5 \\
\hline
\end{tabular}

Table 7: Parameter estimates.

\begin{tabular}{|c|c|c|c|c|c|c|}
\hline \multicolumn{2}{|c|}{ Agricultural land use change* } & \multirow{2}{*}{$\frac{\mathrm{B}}{5.365}$} & \multirow{2}{*}{$\begin{array}{c}\text { Std. error } \\
10.462\end{array}$} & \multirow{2}{*}{$\frac{\text { Wald }}{0.263}$} & \multirow{2}{*}{$\begin{array}{c}\text { Sig. } \\
0.608\end{array}$} & \multirow{2}{*}{$\frac{\operatorname{Exp}(\mathrm{B})}{-}$} \\
\hline LOGIT 1 & Intercept & & & & & \\
\hline \multirow{11}{*}{$\ln \left[\frac{p \text { (AGR-Medium })}{p \text { (AGR-Low })}\right.$} & $X_{1}$ & 0.547 & 0.340 & 2.587 & 0.098 & 1.728 \\
\hline & $X_{2}$ & 3.367 & 3.780 & 0.794 & 0.373 & 28,997 \\
\hline & $X_{3}$ & -12.852 & 9.572 & 1.803 & 0.095 & $2.62 \times 10^{-6}$ \\
\hline & $X_{4}$ & 1.517 & 2.745 & 1.009 & 0.315 & 4.560 \\
\hline & $X_{5}$ & -0.135 & 2.163 & 0.004 & 0.950 & 0.874 \\
\hline & $X_{6}$ & 0.647 & 1.396 & 0.215 & 0.643 & 1.911 \\
\hline & $X_{7}$ & -1.058 & 0.959 & 1.217 & 0.270 & 0.347 \\
\hline & $X_{8}$ & -0.137 & 0.120 & 1.294 & 0.255 & 0.872 \\
\hline & $X_{9}$ & 0.076 & 0.044 & 2.940 & 0.086 & 1.079 \\
\hline & $X_{10}$ & 1.258 & 1.956 & 0.063 & 0.802 & 3.521 \\
\hline & $X_{11}$ & 4.568 & 1.534 & 8.863 & 0.003 & 96.354 \\
\hline LOGIT 2 & Intercept & 10.181 & 12.940 & 0.619 & 0.431 & - \\
\hline \multirow{11}{*}{$\ln \left\lfloor\frac{p \text { (AGK-H1gn })}{p \text { (AGR-Low })}\right\rfloor$} & $X_{1}$ & 0.659 & 0.406 & 2.641 & 0.097 & 1.933 \\
\hline & $X_{2}$ & -11.030 & 7.599 & 2.107 & 0.147 & $1.62 \times 10^{-5}$ \\
\hline & $X_{3}$ & -1.780 & 8.919 & 0.040 & 0.842 & 0.169 \\
\hline & $X_{4}$ & 0.001 & 0.000 & 2.938 & 0.087 & 1.001 \\
\hline & $X_{5}$ & -6.477 & 3.539 & 3.349 & 0.067 & 0.002 \\
\hline & $X_{6}$ & 1.313 & 2.229 & 0.347 & 0.556 & 3.719 \\
\hline & $X_{7}$ & -1.469 & 1.276 & 1.325 & 0.250 & 0.230 \\
\hline & $X_{8}$ & -0.251 & 0.141 & 3.144 & 0.076 & 0.778 \\
\hline & $X_{9}$ & -0.131 & 0.116 & 1.284 & 0.257 & 0.877 \\
\hline & $X_{10}$ & 1.073 & 1.567 & 3.852 & 0.050 & 2.927 \\
\hline & $X_{11}$ & 4.507 & 1.643 & 7.523 & 0.006 & 90.646 \\
\hline
\end{tabular}

*The reference category is low agricultural land use change. 
(depending on the logit that the $\operatorname{Exp}(\mathrm{B})$ is assigned to) for a one-unit change in the predictor variable. Using the estimations of Table 7, the eqns (4) and (5) for the two logits are given below:

$$
\begin{aligned}
\text { LOGIT } 1= & \ln \left[\frac{p(\text { AGR-Medium })}{p \text { (AGR-Low })}\right] \\
= & 5.365+0.547 X_{1}+3.367 X_{2}-12.852 X_{3}+1.517 X_{4} \\
& -0.135 X_{5}+0.647 X_{6}-1.058 X_{7}-0.137 X_{8} \\
& +0.076 X_{9}+1.258 X_{10}+4.568 X_{11} \\
\text { LOGIT } 2= & \ln \left[\frac{p(\text { AGR-High })}{p(\text { AGR-Low })}\right] \\
= & 10.181+0.659 X_{1}-11.030 X_{2}-1.780 X_{3}+0.001 X_{4} \\
& -6.477 X_{5}+1.313 X_{6}-1.469 X_{7}-0.251 X_{8}-0.131 X_{9} \\
& +1.073 X_{10}+4.507 X_{11}
\end{aligned}
$$

Overall, the analysis suggests that in logit 1 , the significant predictors at $10 \%$ level of significance are $X_{1}$ urban sprawl, $X_{3}$ changes in non-urban population, $X_{9}$ investment in agriculture and $X_{11}$ geographical zone. As regards logit 2 , the significant predictors at $10 \%$ level of significance are $X_{1}$ urban sprawl, $X_{2}$ changes in forest land uses, $X_{4}$ population potential, $X_{5}$ changes in irrigated areas, $X_{8}$ the prosperity level, $X_{10}$ animal production and $X_{11}$ the geographical zone.

The coefficient of $X_{1}$ variable (urban sprawl) has a positive sign and it is significant in both logits. The effects of the variable are similar in both categories of agricultural decrease (namely medium and high). With $1 \%$ rise in urban sprawl, the likelihood of a prefecture being in the category of medium agricultural land use change increases by a factor of 1.728, and being in high agricultural land use change by a factor of 1.933 . Hence, in both categories of prefectures, urban sprawl consumes agricultural land. This indicates that the highest rent effect of von Thünen's and Ricardo's theories drive lands away from agriculture. In this way, any parcel of land is ultimately used in the way that generates the highest rent. In addition, this result is in line with the fact that urban sprawl is easier to happen on agricultural land than on forest land due to the fact that forest land areas have a strong degree of protection under the Hellenic Constitution.

The coefficient of $X_{2}$ variable (deforestation) is insignificant in both logits and it is positive in logit 1 and negative in logit 2 . This suggests that forest land use changes are an important causal factor neither for medium nor for high agricultural land use change prefectures. These opposite signs indicate that an increase in deforestation decreases the probability of a prefecture being in the category of high agricultural land use change, but increases the probability of a prefecture being in the medium agricultural land use category. The reduced likelihood of a prefecture being in the 'high' category when the forests in this prefecture decrease means that it might be a conversion of forest land to agricultural land. On the other hand, the increased probability of a prefecture being in the medium agricultural land use change category when its forests decrease means that in these prefectures the lost forest land is not suitable for agricultural purposes or that there is not enough interest for converting forest land to agricultural land.

As regards the predictor variable $X_{3}$ (change in rural population), the coefficient is negative and significant in logit 1 and negative and insignificant in logit 2 . This suggests that an increase in rural population decreases the likelihood that a prefecture is in 'medium' or 'high' agricultural land use change category. In other words, the rural-urban migration processes have had a negative effect on 
agriculture through the abandonment of agricultural land. The influence of the variable seems to be more significant in the prefectures with medium reduction in agricultural land. This might mean that high rates of agricultural land reduction cannot be accounted for by rural population changes. Possibly, some other factors may contribute to a more significant extent to agricultural land reduction.

The coefficient of $X_{4}$ variable (population potential) is positive in both logits but insignificant in logit 1 and significant in logit 2 . This suggests that an increase in population potential results in the reduction of agricultural land (because it increases the likelihood of a prefecture being in the 'medium' or 'high' category in relation to the 'low' category). Therefore, it can be said that the large population concentrations and the interregional distances influence the agricultural land uses. It is likely that this happens because of the increasing demand for urban land. This suggestion is further strengthened considering the influence of variable $X_{1}$ concerning urban sprawl.

The variable $X_{5}$ (change in irrigated areas) has negative coefficients in both logits. However, the variable is statistically significant only in logit 2 . Hence, the availability of water resources and the opportunity of irrigating the cultivated land decrease the likelihood that a prefecture will experience high or medium reduction in its agricultural land. This is logical as irrigation has a positive effect on crop yield and a greater variety of crops can be applied. In total, irrigation increases the profitability of cultivated land.

The coefficient of $X_{6}$ variable (change in hotel beds) is positive and insignificant in both logits. Therefore, it can be inferred that there is a relationship between tourism and agricultural land use change, but it is not significant. Nevertheless, an increase in hotel beds increases the likelihood that a prefecture will experience medium or high agricultural land reduction. The fact that this variable is not significant might be due to the uneven distribution of tourist phenomenon among the Greek prefecture. In some prefecture, the influence may be low or unimportant. In addition to this, the tourist phenomenon and the related infrastructure take place both in urban and non-urban areas. Presumably, tourist hotels in urban areas do not relate to agricultural land uses.

The coefficient of $X_{7}$ variable (change in GDP in agriculture) is negative but statistically insignificant in both logits. That means that there is not a strong relationship between $X_{7}$ variable and the rate of agricultural land use change in the Greek prefectures. However, the negative sign is logical and meets the initial expectations. The growth of GDP in agricultural sector decreases the likelihood of agricultural land being abandoned. This evidence suggests that when the agricultural sector is more profitable, the farmers' incomes increase and there is less scope in converting agricultural land to other land uses.

As regards the predictor variable $X_{8}$ (change in prosperity level), the coefficient is negative and insignificant in logit 1 and negative and statistically significant in logit 2 . This suggests that, at least, for the prefectures in the high agricultural land use change category, the level of prosperity is highly connected to the reduction of agricultural land. Namely, in the prefectures that experience high agricultural land abandonment, there is also a decrease in the level of prosperity. In these areas, it seems that no other economic activity and associated land use managed to replace the decreasing agricultural activities. The land remains undeveloped and the prosperity level decreases.

The coefficient of $X_{9}$ variable (investment in agriculture) is positive and statistically significant in logit 1 and negative and statistically insignificant in logit 2 . These opposite signs indicate that an increase in the investment in agriculture decreases the probability of a prefecture being in the category of high agricultural land use change, but increases the probability of a prefecture being in the medium agricultural land use category. The investments represented by this variable include mainly investments in machinery and investments for creating new infrastructure or improving existing infrastructure in the cultivated land plots. The results indicate that these investments do not lead to an increase in the cultivated land; animals are allowed to graze freely and are fed by access to natural foods in pastures. 
An increase in the indoor production systems of intensively farmed livestock increases the demand for human-provided food and thus the need for additional agricultural land for producing that food. On the other hand, an increase in the traditional livestock farming methods, where animals are allowed to graze freely, increases the demand for pastures potentially at the expense of cultivated land.

The coefficient of $X_{10}$ variable (livestock production) is positive and statistically significant in logit 1 and negative and statistically insignificant in logit 2 . Again the opposite signs indicate that an increase in the product of the livestock-raising sector decreases the probability of a prefecture being in the category of high agricultural land use change, but increases the probability of a prefecture being in the medium agricultural land use category. Livestock raising refers to the indoor production systems of intensively farmed livestock, to the enclosure of livestock in small crates or to larger fenced pastures as well as to the traditional livestock farming methods where animals are allowed to graze freely and are fed by access to natural foods in pastures. An increase in the indoor production systems of intensively farmed livestock increases the demand for human-provided food and thus the need for additional agricultural land for producing that food. On the other hand, an increase in the traditional livestock farming methods where animals are allowed to graze freely increases the demand for pastures potentially at the expense of cultivated land.

As regards the last predictor variable $\mathrm{X}_{11}$ (geographical zone), the coefficient is positive and statistically significant in both logits. This suggests that as the geographical category increases so does the likelihood that a prefecture is in the medium and high agricultural land use change categories. The geographical zones relate to the climatological conditions found in each prefecture. The results show that as we move to milder climatic conditions there is an increase in the likelihood of larger reduction in agricultural land. This might mean that in these areas the conditions favour only the most profitable crop types.

\section{CONCLUSIONS}

Making informed agricultural policy decisions is central to achieving sustainability in rural areas. Prior to formulating certain policy objectives and targets, the baseline information which is needed is the driving force that influences the current agricultural patterns. Broadly speaking, these driving forces are closely associated with the economic and social context within which the regions exist and function. The effects of the predictor variables employed by this study on cultivated land while significant in most regions are still covered with many uncertainties. The evidence suggests that agriculture is highly influenced by urban sprawl due to low institutional protection of cultivated land, deficient and inapplicable land use planning by the state and the highest rent effect of von Thünen and Ricardo theories.

Rural population level is an important issue in halting agricultural land changes, but significant uncertainties arise considering the influence of population potential. The improvements in transportation infrastructure and the changing structure of the large and medium size urban concentrations in Greece puzzle the overall effect of population on agriculture. The model might need further refinement in order to account for the complex effects of population.

New agricultural practices and technological improvements are serious determinants of agricultural land use change. Increases in irrigated areas and the effective use of water resources increase the profitability of cultivated land, so does investment in agriculture. More specifically, investments in machinery and infrastructures improve the efficiency of existing agricultural land. Furthermore, these types of investment increase the capacity of the agricultural sector to adjust to policy reforms. Finally, the positive changes in GDP in agriculture make the agricultural sector more profitable and the farmers more reluctant in converting agricultural land to other land uses.

Future work with this type of model might be necessary to focus on disaggregating the agricultural use issue into subsectors of agriculture and different types of crop. Quite interesting would be the 
investigation of the issue at the municipality level (NUTS IV) when the relevant data would be available, introducing more sophisticated and spatially explicit geographical variable, for example, coastal locations, mountainous locations, etc. The presented methodology is a step towards a detailed approach of agricultural land use changes. Improved prognosis about the future synthesis of land use change patterns and effective policy formulation presuppose thorough understanding of past and current land use/land cover changes trends. The reform of any structural funding policy needs sound information and improved quantification of the forces that bring about land use changes in order to reduce uncertainty in projections and succeed in achieving the objectives of greater economic and social cohesion and lower regional disparities.

\section{REFERENCES}

[1] NSSG: Statistical Yearbook of Greece, Piraeus, 2003.

[2] Rezitis, A.N., Tsiboukas, K. \& Tsoukalas, S., Measuring technical efficiency in the Greek agricultural sector. Applied Economics, 34(11), pp. 1345-1357, 2002. doi:10.1080/00036840110099261

[3] Yiannaka, A., Giannakas, K. \& Tran K.C., Medium, message and advertising effectiveness in the Greek processed meats industry. Applied Economics, 34(14), pp. 1757-1763, 2002. doi:10.1080/00036840110118755

[4] Eurostat: Agriculture, Forestry and Fisheries. Statistical Yearbook, Strasbourg/Brussels, 2005.

[5] Commission of European Communities: Directions towards sustainable agriculture, COM (1999) 22 final, Brussels, 1999.

[6] Council of the EU: Regulation (EC) No 1698/2005 of 20 September 2005 on support for rural development by the European Agricultural Fund for Rural Development (EAFRD). Official Journal of the European Union, 2005.

[7] European Commission, Trends of Some Agri-environnemental Indicators in the European Union, Report EUR 21565 EN, 2005.

[8] Baldock, D., Dwyer, J. \& Sumpsi Vinas, J., Environmental Integration and the CAP: A Report to the European Commission, DG Agriculture. Edited by Policy IotEE, 2002.

[9] Thompson, A.R., Agriculture in future rural landscapes: opportunities through innovative research in applied biology. Annals of Applied Biology, 146(2), pp. 135-136, 2005. doi:10.1111/ j.1744-7348.2005.050036.x

[10] Tilman, D., Global environmental impacts of agricultural expansion: the need for sustainable and efficient practices. Proceedings of the National Academy of Sciences of the United States of America, 96(11), pp. 5995-6000, 1999. doi:10.1073/pnas.96.11.5995

[11] Tilman, D., Fargione, J., Wolff, B., et al., Forecasting agriculturally driven global environmental change. Science, 292(5515), pp. 281-284, 2001. doi:10.1126/science.1057544

[12] Butler, S.J., Vickery, J.A. \& Norris, K., Farmland biodiversity and the footprint of agriculture. Science, 315(5810), pp. 381-384, 2007. doi:10.1126/science.1136607

[13] Boatman, N., Stoate, C., Cooch, R., et al., The Environmental Impacts of Arable Crop Production in the European Union: Practical Option for Improvement. Edited by Commission E, 1999.

[14] Rahman, S., Environmental impacts of technological change in Bangladesh agriculture: farmers' perceptions, determinants, and effects on resource allocation decisions. Agricultural Economics, 33(1), pp. 107-116, 2005. doi:10.1111/j.1574-0862.2005.00284.x

[15] NSSG: Pre-census Data of the Agriculture and Livestock Census 1999/2000, Piraeus, 2001.

[16] Briassoulis, H. \& van der Straaten, J., Tourism and the environment: an overview. Tourism and the Environment, 2nd revised edn, eds H. Briassoulis \& J. van der Straaten, Kluwer Academic Publishers: Dordrecht, 2000. 
[17] Lambin, E.F., Rounsevell, M.D.A. \& Geist, H.J., Are agricultural land-use models able to predict changes in land-use intensity? Agriculture, Ecosystems \& Environment, 82(1-3), pp. 321-331, 2000. doi:10.1016/S0167-8809(00)00235-8

[18] Verburg, P.H., Ritsema van Eck, J.R., de Nijs, T.C.M., et al., Determinants of land-use change patterns in the Netherlands. Environment and Planning B: Planning and Design, 31(1), pp. 125-150, 2004. doi:10.1068/b307

[19] Lesschen, J.P., Verburg, P.H. \& Staal, S.J., Statistical Methods for Analysing the Spatial Dimension of Changes in Land Use and Farming Systems - LUCC Report Series 7, The International Livestock Research Institute, Nairobi, Kenya and LUCC Focus 3 Office, Wageningen University, the Netherlands, 2005.

[20] Polyzos, S., Christopoulou, O., Minetos, D., et al., An overview of urban-rural land use interactions in Greece. International Journal of Agricultural Resources, Governance and Ecology, 7(3), pp. 276-296, 2008.

[21] MacDonald, D., Crabtree, J.R., Wiesinger, G., et al., Agricultural abandonment in mountain areas of Europe: environmental consequences and policy response. Journal of Environmental Management, 59(1), pp. 47-69, 2000. doi:10.1006/jema.1999.0335

[22] Kleijn, D. \& Sutherland, W.J., How effective are European agri-environment schemes in conserving and promoting biodiversity? Journal of Applied Ecology, 40(6), pp. 947-969, 2003. doi:10.1111/j.1365-2664.2003.00868.x

[23] Lambin, E.F., Turner, B.L., Geist, H.J., et al., The causes of land-use and land-cover change: Moving beyond the myths. Global Environmental Change, 11(4), pp. 261-269, 2001. doi:10.1016/S0959-3780(01)00007-3

[24] NSSG: Pre-census data of the Agriculture and Livestock Census of the year 1990/1991, Piraeus, 1995.

[25] NSSG: Census of buildings, Hellenic Republic, Athens, 1990.

[26] NSSG: Census of buildings, Piraeus, 2000.

[27] Leontidou, L., Afouxenidis. A., Kourliouros, E., et al., First Greek Annual Report: Causes of Urban Sprawl in Athens \& East Attica, 1981-2001, Hellenic Open University, 2001.

[28] Hubacek, K. \& van den Bergh, J., The Role of Land in Economic Theory. Interim Report IR-02-037, International Institute for Applied Systems Analysis: Laxenburg, Austria, 2002.

[29] Lambrianidis, L., Economic Geography: Theories and Empirical Examples, 7th edn, Patakis Publications: Athens, 2006.

[30] NSSG, Population Census, Piraeus, 1991.

[31] NSSG, Population Census, Piraeus, 2001.

[32] Zelinsky, W., The hypothesis of the mobility transition. Geographical Review, 61(2), pp. 219-249, 1971. doi: $10.2307 / 213996$

[33] Leontidou, L., Cities of Silence: Working Class Colonisation of Urban Space, Athens and Pireaus 1909-1940, Cultural and Technological Institution of the National Bank of Industrial Development of Greece (ETBA), Athens, 1989.

[34] Polyzos, S. \& Arambatzis, G. Labor productivity of agricultural sector in Greece: determinant factors and interregional differences analysis. New Medit, Mediterranean Journal of Economics, Agriculture and Environment, 1, pp. 58-64, 2006.

[35] Minetos, D., Polyzos, S. \& Sdrolias, L., Social and public responsibility and illegal urban land uses in Greece: an empirical investigation. MIBLE-Management of International Business \& Economic Systems Conference, Larissa-Greece, Department of Business Administration, School of Business and Economics, T.E.I. of Larissa, 2006. 
[36] Petrakos, G. \& Polyzos, S., Regional inequalities in Greece: literature review and estimations of inequalities. Studies in Greek Economy, vol. 1, eds M. Chletsos, C. Kollias \& H. Naxakis. Patakis: Athens, 2005.

[37] Siardos, G., Methods of Multivariate Statistical Analysis, 3rd edn, vol. 2. Stamoulis Publications (in Greek): Athens, 2005.

[38] Norusis, M., SPSS 13, Advanced Statistical Procedures Companion. Prentice Hall Inc: New Jersey, 2004.

[39] Morita, H., Hoshino, S., Kagatsume, M., et al., An application of the land-use change model for the Japan case study area. Working Papers ir97065, International Institute for Applied Systems Analysis, Laxenburg, Austria, 1997.

[40] Chowdhury, R.R., Driving forces of tropical deforestation: the role of remote sensing and spatial models. Singapore Journal of Tropical Geography, 27(1), pp. 82-101, 2006. doi:10.1111/j.1467-9493.2006.00241.x

[41] Newburn, D.A., Berck, P. \& Merenlender, A.M., Habitat and open space at risk of land-Use conversion: targeting strategies for land conservation. American Journal of Agricultural Economics, 88(1), pp. 28-42, 2006. doi:10.1111/j.1467-8276.2006.00837.x

[42] NSSG: Statistical Yearbook of Greece, Athens, Hellenic Republic, 2001.

[43] Kaimowitz, D. \& Angelsen, A., Economic Models of Tropical Deforestation: A Review, Center for International Forestry Research: Jakarta, Indonesia, 1998.

[44] Mahapatra, K. \& Kant, S., Tropical deforestation: A multinomial logistic model and some country-specific policy prescriptions. Forest Policy and Economics, 7(1), pp. 1-24, 2005. doi:10.1016/S1389-9341(03)00064-9 